\title{
Spatial modeling and interpolation of monthly temperature using kriging
}

\author{
Margaret R. Holdaway* \\ Mathematical Statistician, USDA Forest Service, North Central Forest Experiment Station, 1992 Folwell Avenue, \\ St. Paul, Minnesota 55108, USA
}

\begin{abstract}
Estimates of the climatic record at forest plot locations may be useful in studying how forests will respond to future climatic change. Kriging was applied to the spatial interpolation of monthly temperature records in the forested regions of Minnesota in the north central United States. Monthly empirical variograms, averaged over $90 \mathrm{yr}$, were modeled with Gaussian or linear models, and ordinary kriging was applied to interpolate the data. Anisotropies were found in the winter months, suggesting the presence of a large-scale regional trend. Structural analysis of mean monthly temperature revealed: (1) a broad regional component to the variation, changing systematically by month, which was estimated by a linear function of latitude and longitude and (2) a lake effect (due to Lake Superior) varying in strength and sign by month. A detrending approach was tested to remove these effects and a modified approach based on only the lake effect trend was also tested. The cross validation technique was used to test the 3 models. The lake effect trend model was judged best in accounting for the influence of Lake Superior on nearby land areas. The study demonstrated that moderate trends in the data do not seriously degrade the applicability of ordinary kriging to the interpolation of monthly temperature. A temporal analysis revealed that, although there have been systematic changes in the spatial variability over the last century, using century-averaged variograms is not expected to decrease the accuracy and precision of the interpolations.
\end{abstract}

KEY WORDS: Geostatistics · Residual kriging · Semivariogram modeling $\cdot$ Lake effect $\cdot$ Minnesota

\section{INTRODUCTION}

There is growing concern over the effect increased concentrations of carbon dioxide and other 'greenhouse' gases in the atmosphere could have on climate and therefore on forest ecosystems. To predict accurately how forests will respond to future climatic change, we must understand how climate affects the forest ecosystem. Two approaches are possible: (1) a temporal emphasis that relates historical records of change in tree growth, mortality, and regeneration to historical climatic records, or (2) a spatial emphasis that relates forest dynamics in widely separated locations with the distinct climate found there. Until recently, the climatic variables used in both

\footnotetext{
•E-mail: holda001@maroon.tc.umn.edu
}

approaches were generally estimated from the values recorded at the nearest weather station. Often, however, forest research plots are located in areas substantially distant from a weather station.

Climatic measurements from meteorological stations are spatially arrayed in an irregular, coarse grid, often providing only sparse coverage of the more forested areas. In addition, large bodies of water may have a noticeable effect on the temperature regime of nearby land areas (e.g. Lake Superior on northeast Minnesota, USA). (Elevation may also be an important factor in determining temperature in some areas, but not in non-mountainous regions.) Further, there is also a broad regional northerly displacement of temperature and at times a weaker longitudinal effect. Temperature estimates at plot locations are needed that take into account the temperature-lake effect relationship and the latitude-longitude effect. 
Estimating values at unsampled locations is an interpolation problem. Kriging is a sophisticated geostatistical technique used in the spatio-temporal interpolation. of geographic data. It has been found superior to other commonly used interpolation techniques for precipitation estimation (Tabios \& Salas 1985). Kriging provides unbiased interpolation with minimum mean square estimation error. Its other strengths include its ability to incorporate information about regional and local trends. The technique has been used frequently in soil science (Burgess \& Webster 1980, Webster \& Burgess 1983) and hydrology (Delhomme 1978). More recently kriging has been implemented in forestry (Samra et al. 1989), ecology (Seilkop \& Finkelstein 1987, Lefohn et al. 1988, Fortin et al. 1989) and climatology. Within climatology, geostatistics has been usually applied to the analysis of precipitation (Dingman et al. 1988, Bigg 1991, Dolph \& Marks 1992, Phillips et al. 1992) or evapotranspiration (Martinez-Cob \& Cuenca 1992), but seldom directly to the analysis of temperature.

Kriging deals with variables (called 'regionalized' variables) distributed in space and/or time. The spatial variation of a regionalized variable has a structured component - a measure of the similarity between close observations - and a random component (Journel \& Huijbregts 1978). The 2 components are represented in the variogram, a mathematical description of the spatial variability. Kriging uses the variogram to assign weights to neighboring observations in the interpolation process.

The work described in this paper is limited to the forested regions of Minnesota. The general objective is to analyze and model the spatial variability and patterns of monthly temperature, thus providing the necessary information to interpolate temperature spatially. A preliminary assessment is made of the accuracy of the spatial patterns to describe the regional temperature characteristics adequately. Then with cross validation, 2 kriging models are tested to interpolate monthly temperature. The goal is to investigate the improvement in accuracy of the interpolation by using detrending to account for the lake effect and the latitude-longitude effect. Finally, a simplified alternative model is suggested, and that model is used to evaluate the effect of century-long temporal changes in the spatial variability on the model's predictive capabilities

\section{OVERVIEW OF KRIGING WITH TRENDS}

Ordinary kriging, one of the simplest forms of kriging, assumes that the data are stationary, i.e. they contain no significant trends (or drift) over the spatial range (Journel \& Huijbregts 1978). However, many regionalized variables show local trends or even broader regional trends when spatially analyzed. These trends are usually not a problem because the stationarity assumption applies only to the search neighborhood used in the interpolation-which may be reasonably homogeneous-and not to the entire data set. To remedy the nonstationarity problem when the trend becomes too large, universal kriging was developed. Its simpler form, residual kriging, can also be used to 'detrend' the data. Detrending is useful in dealing with broader regional trends or more locally occurring conditions, such as the well-known dependency between rainfall amounts and elevation (Chua \& Bras 1982, Dingman et al. 1988, Phillips et al. 1992, Garen et al. 1994).

A nonstationary regionalized variable can be regarded as having 2 components. The drift represents the systematic trend inherent in the data; the residual is the difference between the actual measurements and the drift. Obviously, if the drift is removed from a regionalized variable, the residuals will be more stationary, and ordinary kriging can be applied to them. In residual kriging, the drift or trend is estimated by a mathematical function and is then removed from the data. The underlying variogram of the residuals is calculated in the usual way, and the residuals are kriged to obtain estimates. Finally, the drift is added back to the estimated residuals to produce the final result.

In Minnesota the modifying influence of Lake Superior on climate in the northeast corner of the state is a locally occurring trend. Analysis of stations near Lake Superior will determine the lake effect. Larger scale trends may also relate to natural processes that operate in defined directions, such as the effect of progressively increasing latitude. The climatological mean temperature field can be used to represent this trend. Analyzing the regression of mean temperature on location for each month will identify the presence of any large-scale trends, whether due to latitude or even a longitude effect.

\section{STUDY AREA}

\subsection{Data}

This paper presents spatial analysis of monthly temperature data in northern and central Minnesota. Data from meteorological observation stations of the NOAA Network of Climatic Data Acquisition Stations were obtained from the Minnesota State Climatology Office. Monthly temperature data were compiled from 1900 through May 1993. Only those stations with less than $40 \%$ missing observations were included in the analysis. Such a high cutoff value was necessary because many stations did not start recording temperature until 
the late 1920 s or early 1930 s. The stations used were limited to those located in the northern half of the state, which corresponds to the forested region of the state. An envelope of additional stations to the west was included to cover the edge of the transition to prairie. No stations were included below $45^{\circ} 30^{\prime} \mathrm{N}$ latitude, which eliminated a few stations in forested counties closer to the Minneapolis/St. Paul metropolitan area. Thirty-five stations met the forest and latitude requirements (Table 1, Fig. 1).

\subsection{Climate}

In this region, large-scale weather processes are mainly determined by air masses, frontal systems, and average storm tracks, which in turn may be modified to an unusual degree by proximity to large bodies of water. The overall effect of these 4 factors on temperature is fairly stable over longer time intervals, and, except for the lake effect, all can be expressed as a function of the latitude and longitude.

Dominant weather patterns for Minnesota have been described by Baker \& Kuehnast (1978). During January, the state is dominated by cold, dry northwest winds out of the interior of Canada. This trend continues in the other winter months, starting as early as November and continuing intermittently into March. Warm moist air from the Gulf of Mexico first arrives in March and predominates through the summer months. Southwest winds are common in the summer (Baker et al. 1985). September and October are transition months back to winter. The predominant wind direction, which is the integration of the synoptic weather systems for each of these months, deter- mines the strength and direction of the dominant weather effects.

An excellent analysis of the spatial distribution of temperature in Minnesota is given by Baker et al. (1985). To summarize their findings: the 2 major causes of temperature variation are latitude (northward displacement) and longitude (east-west displacement). Temperature decreases from south to north; the temperature gradient is greater in winter than in summer. In the northern half of the state, temperature decreases from west to east in the summer and from east to west

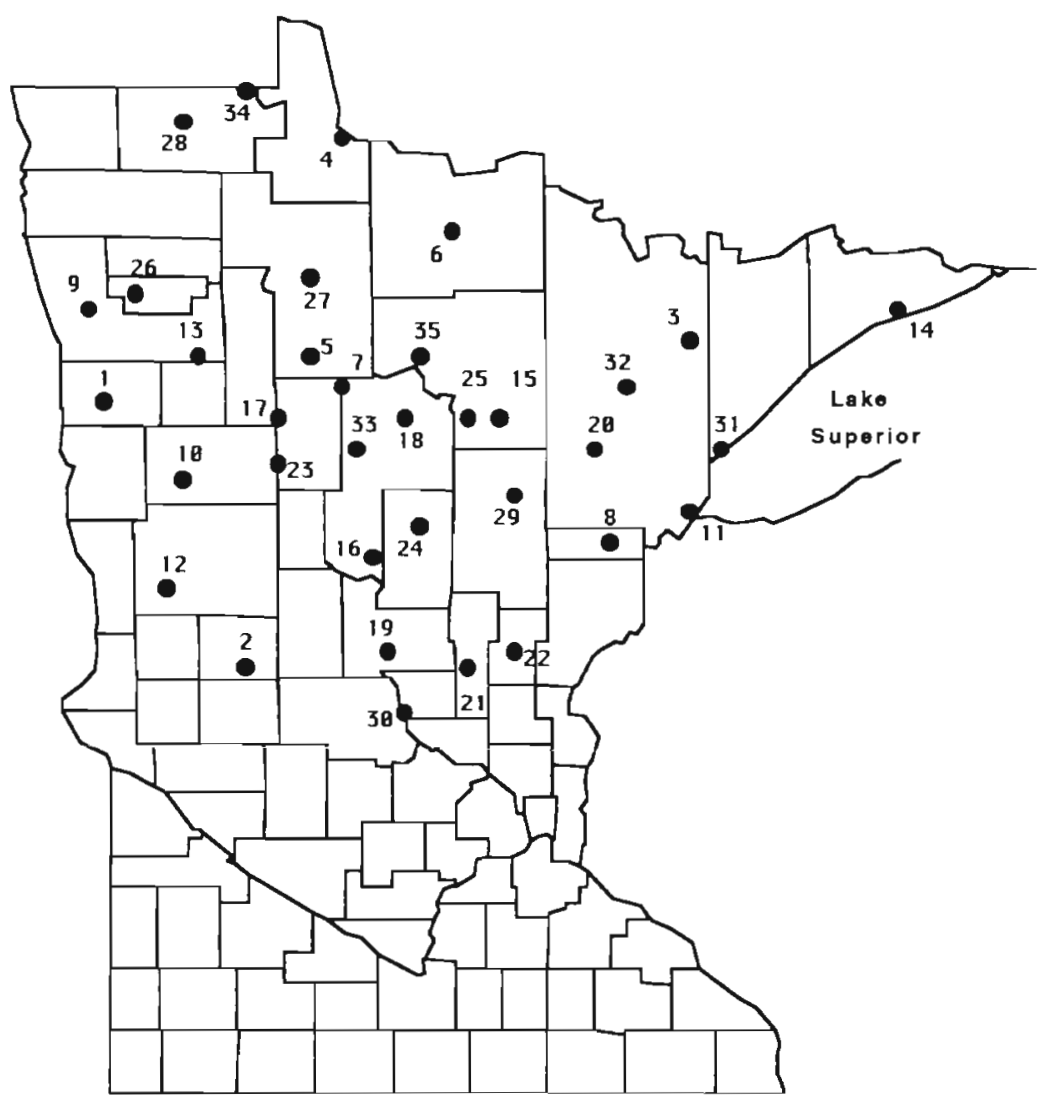

Fig. 1. Location of NOAA meteorological stations in northern Minnesota, USA, with monthly temperature records at least $40 \%$ complete from 1900 through May 1993. Numbers correspond to entries in Table 1

Table 1. Stations used in study of monthly temperature in Minnesota, USA

$\begin{array}{ll}1 \text { Ada } \\ 2 \text { Alexandria } \\ 3 \text { Babbitt } \\ 4 \text { Baudette } \\ 5 \text { Bemidji } \\ 6 \text { Big Falls } \\ 7 \text { Cass Lake } \\ 8 \text { Cloquet } \\ 9 & \text { Crookston }\end{array}$

1 Ada

Alexandria

4 Baudette

5 Bemidji

9 Crookston
10 Detroit Lakes
11 Duluth
12 Fergus Falls
13 Fosston
14 Grand Marais
15 Grand Rapids
16 Gull Lake
17 Itasca
18 Leech Lake Dam

$\begin{array}{ll}19 & \text { Little Falls } \\ 20 & \text { Meadowlands } \\ 21 & \text { Milaca } \\ 22 & \text { Mora } \\ 23 & \text { Park Rapids } \\ 24 & \text { Pine River Dam } \\ 25 & \text { Pokegama Dam } \\ 26 & \text { Red Lake Falls } \\ 27 & \text { Red Lake Indian Agcy }\end{array}$

\author{
28 Roseau \\ 29 Sandy Lake Dam \\ 30 St. Cloud \\ 31 Two Harbors \\ 32 Virginia \\ 33 Walker \\ 34 Warroad \\ 35 Winnibigoshish Dam
}


in the winter. The winter latitude effect is the strongest effect, and in general the latitude effect is stronger than the longitude effect.

The effect of Lake Superior on temperature also needs to be evaluated. Lake Superior acts as a heat reservoir in cool periods and as a cooling source in warm periods. As a result, temperatures along the lake are relatively higher in cold months and cooler in warm months (Baker \& Strub 1965) than would otherwise occur. However, the effect of the lake on the regional climate is minimized both because of prevailing westerly winds and because of the upland that rises abruptly from the lakeshore (Baker \& Strub 1965). Thus, the influence of Lake Superior is of importance only along the immediate lakeshore. Air temperature is modified because of the temperature difference between land and water. The largest difference occurs in December due to the relatively warm lake surface adjacent to the snow-covered land surface (Baker et al. 1985). During much of January the lake is usually still ice-free and warmer than the land. The lake effect on local land temperatures virtually disappears when ice covers the lake during February, March, and into April (Baker et al. 1985). The land is warmer than the lake from April through August, so the lake has a cooling effect on adjacent land areas.

Elevation has a minimal effect on temperature in Minnesota. In northern and central Minnesota retreating glaciers left a landscape of flat rolling terrain interrupted by areas of low hills, lakes and wetlands. Glacial action also formed a few ranges in the northeast (an area of very sparse weather station coverage) and an area of high terrain near Itasca known as the Alexandria Moraine. None of the areas rises more than $250 \mathrm{~m}$ above the general level of the surrounding region. Nevertheless, a distinctly cooler area is associated with the Alexandria Moraine, which in the summer enlarges eastward (Baker et al. 1985).

\section{VARIOGRAM MODELING}

The variogram describes the spatial variability of a regionalized variable. At least 50 weather stations are usually needed as a minimum to estimate the variogram fairly well (Bilonick 1983). If the network of stations is not dense enough, reasonably good average estimates of the theoretical variogram may often be gained by pooling variograms over a temporally stationary time interval (Bilonick 1983). Estimating a separate variogram for each month over the 90 yr would ideally be the most accurate procedure. However, this approach would be extremely time-intensive to apply, and the sparseness of the data would make it difficult to reliably estimate the individual variograms. Instead, data pairs for all 90 years were pooled to produce century-averaged monthly variograms. This was accomplished by modifying the source code of the kriging algorithm from Geo-EAS 1.1 (Englund \& Sparks 1988) to aggregate observation pairs by month over the entire time period. Thus, the variogram used has the same form for each month regardless of the year. The assumption that the spatial variability has not changed over the last century and the effect of that assumption on interpolation accuracy will be more fully evaluated later in the paper.

Because screening for inconsistent data pairs is difficult with such a large data base, a simplified approach was used. Examination of monthly mean temperatures by station revealed that mean values for the 3 stations on Lake Superior showed distinct features. Grand Marais and Two Harbors differed by 2 to $4^{\circ} \mathrm{C}$ from other stations in their general vicinity, varying in magnitude by month and in sign by winter or summer season. Duluth showed a similar, but less marked effect. Thus, for estimating the underlying regional variogram without confounding it by the strong lake effect, the Grand Marais and Two Harbors observations were removed.

Omnidirectional variograms (irrespective of direction) were modeled first by fitting a curve to the experimentally measured data. Monthly experimental variograms based on data from 33 weather stations pooled over $90 \mathrm{yr}$ are plotted in Fig. 2. Months having similar variograms were grouped using a clustering procedure. Distance classes of $40 \mathrm{~km}$ were used. Overall, the monthly variograms for the screened data (with Grand

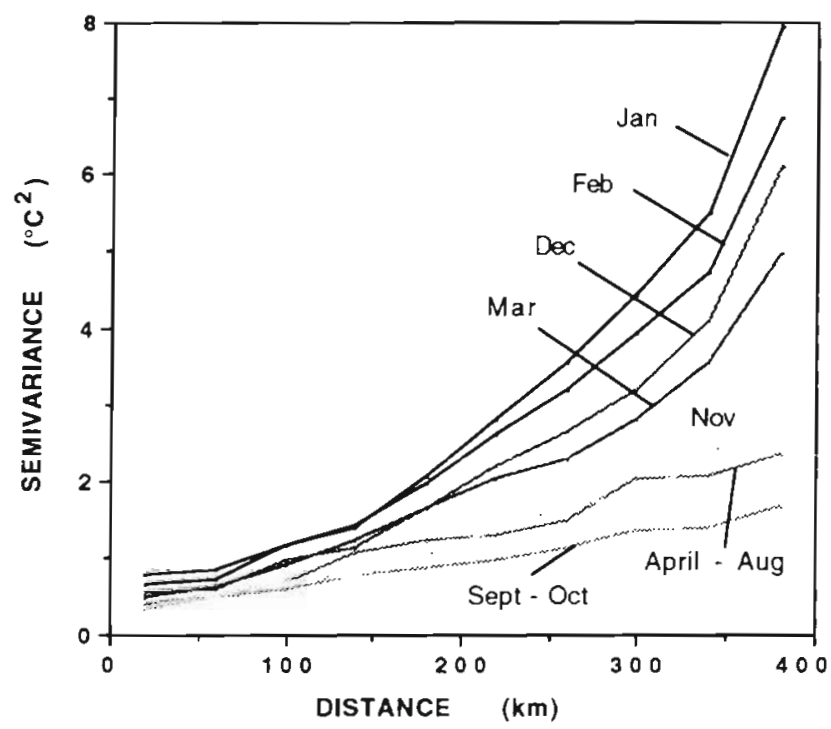

Fig. 2. Empirical variograms of NOAA 1900-1993 monthly temperature data. (April - Aug represents average of April through August) 
Table 2. Parameters (nugget effect, $C_{0}$ i sill, $C_{0}+C_{i}$ and range, r) for the Gaussian and linear models fit to the monthly temperature variograms

\begin{tabular}{|ccccc|}
\hline Month & Model & $\begin{array}{c}C_{0} \\
\left({ }^{\circ} \mathrm{C}^{2}\right)\end{array}$ & $\begin{array}{c}C_{0}+C \\
\left({ }^{\circ} \mathrm{C}^{2}\right)\end{array}$ & $\begin{array}{c}r \\
(\mathrm{~km})\end{array}$ \\
\hline 1 & Gausian & 0.62 & 19.1 & 1040 \\
2 & Gausian & 0.77 & 19.3 & 1160 \\
3 & Gausian & 0.46 & 14.4 & 1110 \\
4 & Linear & 0.30 & 2.1 & 400 \\
5 & Linear & 0.20 & 3.0 & 400 \\
6 & Linear & 0.20 & 2.7 & 400 \\
7 & Linear & 0.20 & 2.4 & 400 \\
8 & Linear & 0.30 & 2.2 & 400 \\
9 & Linear & 0.25 & 1.7 & 400 \\
10 & Linear & 0.30 & 1.3 & 400 \\
11 & Gausian & 0.40 & 8.7 & 1110 \\
12 & Gausian & 0.52 & 16.0 & 1110 \\
\hline
\end{tabular}

Marais and Two Harbors observations removed) are remarkably well-defined because of the large amount of data.

Experimental variograms for November through March are best described by the Gaussian model with nugget effect given by:

$$
\gamma(h)=C_{0}+C\left[1-\exp \left(-h^{2} / a^{2}\right)\right]
$$

where $C_{0}$ is the nugget effect, $C_{0}+C$ the sill, $r=1.73 a$ the effective range, and $h$ the distance. The models were subjectively fit, since approximately only the first half of the Gaussian function was delineated. No unique solution was possible and hence the sill and ranges cannot be predicted precisely. Still, general observations can be made. The small nugget effect, less than $5 \%$ of the approximate sill, indicates that most of the variation observed is due to spatial variability and not to random variation. The remaining experimental variograms were fit by the linear model. Because a linear model never reaches its range and sill, a 'range' value of $400 \mathrm{~km}$ was chosen so that the corresponding 'sill' results in the slope of the model. Parameters for the models are given in Table 2.

The Gaussian model has behavior similar to a parabola near the origin-indicative of an extremely continuous process. However, drift in the data can also produce gently parabolic variograms of the raw data that are concave upward near the origin (David 1977). The winter curves (November through March) are clearly parabolic. This could indicate the presence of a smoothly varying large-scale trend in winter temperature and hence of unhandled drift. A study of anisotropy in the data confirms this.

Separate variograms were calculated for 8 angle classes $\left(0^{\circ}, 22.5^{\circ}, 45^{\circ}, 67.5^{\circ}, 90^{\circ}, 112.5^{\circ}, 135^{\circ}\right.$, and $157.5^{\circ}$; angular tolerance $\pm 11.25^{\circ}$ ) using distance classes of $65 \mathrm{~km}$ for each month beginning with the

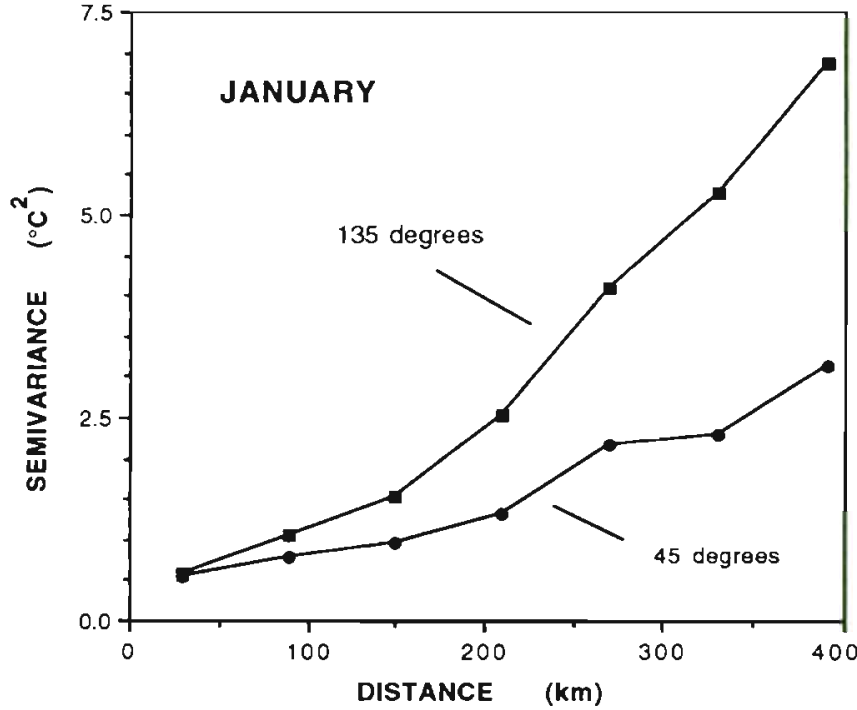

Fig. 3. Anisotropy for January temperature

W-E direction. The winter months from November through March showed definite anisotropy; January exhibited the greatest. January's empirical variograms for the 2 principal directions are shown in Fig. 3. The direction of maximum variation occurs at $135^{\circ}$ and minimum variation at $45^{\circ}$. Thus, a clear anisotropy is displayed in the NW-SE direction. This indicates a trend or drift (Bilonik 1985) in the mean temperature in the NW-SE direction.

\section{TREND MODELING}

\subsection{The trend}

Evidence of nonstationarity in the mean was observed in the variograms for the winter months. This may necessitate the use of residual kriging on these data. Also, a lake effect is present during many months in the year. Two types of information are needed for residual kriging: an estimate of the trend and an estimate of the variogram with the trend removed.

The trend was calculated in $x$ - and $y$-coordinates corresponding to longitude and latitude. Monthly scatterplots of average temperature were clearly linear in $x$ and $y$. A dummy variable, initially set to 1 for the 3 lake stations and 0 for the remaining stations, was added to the trend model to account for the variation caused by Lake Superior. No accounting was made for how far inland stations were located because the lake effect is only present along the immediate shoreline. Thus, only the three stations on the lake were considered to be affected by Lake Superior. Further, it was assumed that the water surface area of Lake Superior 'adjacent' 
to these stations will affect the lake's impact. The dummy variable was modified to account further for the amount of lake surface area around the 3 stations. Modifiers of $(1.00,0.67$, and 0.33$)$ and $(1.00,0.50$, and $0.25)$ at Grand Marais, Two Harbors, and Duluth, respectively, were tested. Over all 12 months, the coefficient of determination $\left(R^{2}\right)$ for the first set was slightly better than for the second set, indicating that the process is not very sensitive to the choice of these values. After dummy variable and modifier were combined, Grand Marais, the station surrounded by the greatest lake surface area, was assigned a 'lake index' of 1.00; Two Harbors, with less water area, was given a 0.67 ; and Duluth, at the tip of the lake, was assigned a 0.33 . All other stations were given lake indices of 0.00 . Average monthly temperature plotted against the $x$ and $y$-coordinates generally confirmed this choice of weights. The final trend model $(m)$ was a multiple linear regression in $x$ (for longitude), $y$ (for latitude), and a lake index: $m(x, y)=A+B x+C y+D$ Lake index.

A cross-product term in $x$ and $y$ was also tested for all 12 months, but it was only significant for November $(p=0.02)$. Its inclusion only minimally increased $R^{2}$, and the cross-product term was disregarded. Parameter values and coefficients of determination $\left(R^{2}\right)$ for the trend model by month are given in Table 3 . A few of the weaker parameters are not significant at $p=0.05$ but have been included to demonstrate the overall pattern. The parameters for the $x$ - and $y$-coordinates are expressed in change in ${ }^{\circ} \mathrm{C}$ per $100 \mathrm{~km}$. Positive values represent increasing temperature with eastward or northward displacement.

Table 3. Trend model parameters for average monthly temperature expressed as a linear function of $x$ - (for longitude) and $y$ - (for latitude) coordinates and a lake index. Coefficients of determination $\left(R^{2}\right)$ from the multiple linear regression analysis are included. $A$ : $y$-intercept, in ${ }^{\circ} C_{i} B$ : Longitude parameter, in ${ }^{\circ} \mathrm{C}$ per $100 \mathrm{~km}$; $\mathrm{C}$ : Latitude parameter, in ${ }^{\circ} \mathrm{C}$ per $100 \mathrm{~km}_{i} D$ : Lake index parameter, in ${ }^{\circ} \mathrm{C}$ (Lake index $=1.00$ for Grand Marais; 0.67 for Two Harbors; and 0.33 for Duluth).

- Not significant at $\mathrm{p}=0.05$

\begin{tabular}{|crrrrr|}
\hline Month & \multicolumn{1}{c}{$A$} & $B$ & $C$ & $D$ & $\mathrm{R}^{2}$ \\
\hline 1 & -12.75 & 0.33 & -1.08 & 4.08 & 0.94 \\
2 & -10.12 & 0.35 & -1.01 & 2.53 & 0.90 \\
3 & -1.87 & $-0.07 \cdot$ & -0.99 & 1.91 & 0.84 \\
4 & 7.48 & -0.42 & -0.74 & $-0.22 \cdot$ & 0.76 \\
5 & 14.49 & -0.55 & -0.56 & -2.53 & 0.82 \\
6 & 19.75 & -0.58 & -0.57 & -3.54 & 0.88 \\
7 & 22.92 & -0.56 & -0.64 & -2.35 & 0.89 \\
8 & 21.69 & -0.61 & -0.65 & $0.10 \cdot$ & 0.83 \\
9 & 16.02 & -0.44 & -0.67 & 0.90 & 0.76 \\
10 & 9.06 & -0.22 & -0.57 & 0.92 & 0.70 \\
11 & -0.52 & $0.01 \cdot$ & -0.77 & 2.65 & 0.87 \\
12 & -8.73 & 0.15 & -1.01 & 4.11 & 0.93 \\
\hline
\end{tabular}

The previous observations of climate patterns (Baker et al. 1985) are thus confirmed. The latitude effect (decreasing with northerly displacement) is generally stronger than the longitude effect (which switches direction from winter to summer). The strongest effect is the northward displacement of about $1^{\circ} \mathrm{C}$ per $100 \mathrm{~km}$ in the winter. Evaluated together, the 2 directional effects indicate that the strongest weather patterns occur in the winter months when the dominant weather systems come out of the interior of Canada (from a NNW direction). The next strongest patterns occur in the hot summer months when the prevailing weather systems come from the southwestern United States

However, all these effects are secondary to the lake effect, which exerts a maximum warming effect at Grand Marais of more than $4^{\circ} \mathrm{C}$ in December and January and a maximum cooling effect of more than $3.5^{\circ} \mathrm{C}$ in June - thus causing a lag in the impact of approaching winter and summer temperatures. When the lake effect is weak in the transition months, $R^{2}$ values range between 0.70 and 0.83 (accounting for the latitudelongitude effect only). In months when the lake effect is strongest, $R^{2}$ values occur in the low to mid 0.90 s.

\subsection{Residual variograms}

The linear trend model with lake effect was subtracted from all observations, and residuals were obtained. The residual temperatures were then used as input into the estimation of the residual variogram (i.e. the underlying variogram free of the trend). Monthly observations from Grand Marais and Two Harbors were included because detrending should have corrected their aberrant behavior. Residual variograms were fit by the linear function for October to March and by the spherical function for the remaining warmer months. The spherical function with nugget effect is given by:

$$
\begin{aligned}
\gamma(h) & =C_{0}+C\left[1.5(h / a)-0.5(h / a)^{3}\right], & & \text { if } h \leq a \\
& =C_{0}+C & & \text { if } h \geq a
\end{aligned}
$$

where $C_{0}$ is the nugget effect, $C_{0}+C$ the sill, a the range, and $h$ the distance. The spherical functions were fit using a simple visual procedure given by David (1977). Models and parameters for the residual variograms by month are given in Table 4 . At the microclimatic scale, nugget effects from 30 to $60 \%$ of the sill indicate that with the removal of the broadscale regional trend and lake effect, up to roughly half of the remaining local variation is random and unpredictable (at the sampling scale used). The initial variogram and residual variogram for January (showing the strongest anisotropy before the winter latitude effect was removed by detrending) are given in Fig. 4 . 
Table 4. Model and parameters for the monthly residual variograms after linear detrending with lake effect. $C_{0}$ is the nugget effect, $C_{0}+C$ the sill, and $r$ the range

\begin{tabular}{|ccccc|}
\hline Month & Model & $\begin{array}{c}C_{0} \\
\left({ }^{\circ} \mathrm{C}^{2}\right)\end{array}$ & $\begin{array}{c}C_{0}+C \\
\left({ }^{\circ} \mathrm{C}^{2}\right)\end{array}$ & $\begin{array}{c}r \\
(\mathrm{~km})\end{array}$ \\
\hline 1 & Linear & 0.50 & 1.00 & 250 \\
2 & Linear & 0.70 & 1.20 & 333 \\
3 & Linear & 0.40 & 1.40 & 400 \\
4 & Spherical & 0.25 & 0.71 & 215 \\
5 & Spherical & 0.30 & 0.80 & 250 \\
6 & Spherical & 0.25 & 0.65 & 225 \\
7 & Spherical & 0.25 & 0.65 & 275 \\
8 & Spherical & 0.30 & 0.62 & 225 \\
9 & Spherical & 0.30 & 0.58 & 275 \\
10 & Linear & 0.35 & 0.70 & 400 \\
11 & Linear & 0.30 & 0.80 & 300 \\
12 & Linear & 0.40 & 1.00 & 300 \\
\hline
\end{tabular}

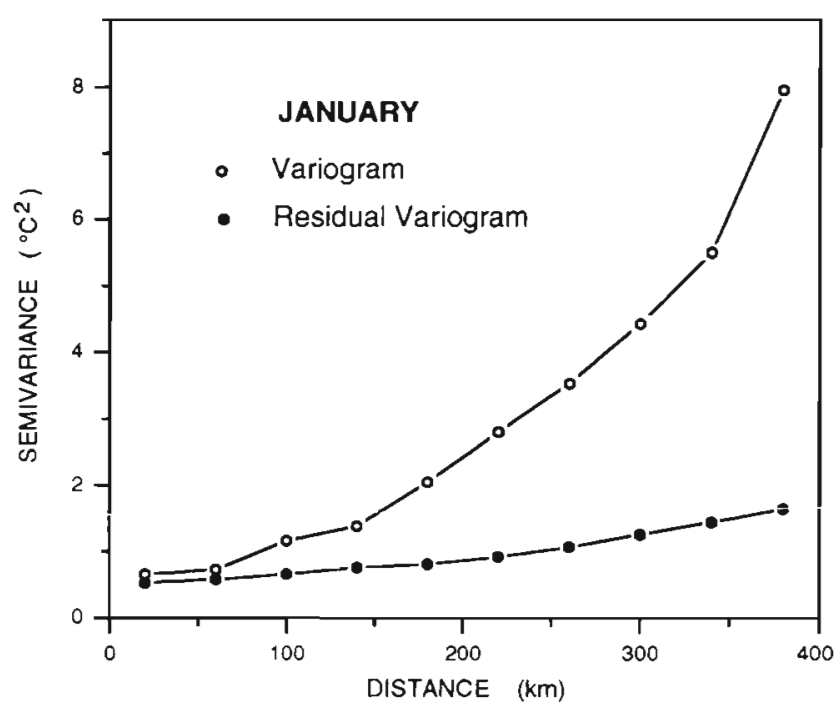

Fig. 4. Empirical variograms and residual variograms for monthly temperature data for January

The difference between the 2 curves represents the effect of the trend on the variation. The strong anisotropy found in January has been reduced but not totally removed.

\subsection{A modified trend model}

Preliminary results indicate that accounting for the average latitude-longitude effects may not increase the accuracy and precision of the basic model. However, the lake effect - a much stronger, more localized effect-may still need to be considered.

As a result, a third model was proposed. Lake effect parameters were calculated in the same manner. Lati- tude and longitude were again used to separate out the lake effect by evaluating temperatures at other stations in the same vicinity but not on the lake. However, the lake effect was applied differently. It was assumed that when estimating temperatures of stations close to Lake Superior, only neighboring stations of fairly similar latitude and longitude were used. Therefore, in the actual kriging of the observations, the trend model used only the lake effect (as given in Table 3) but not the latitude and longitude effect. Because the latitude and longitude effect was not accounted for in the trend model, the initial variograms (see Table 2) were used instead of the residual variograms. This lake effect trend model estimated stations on Lake Superior or relatively near the lake differently than the basic model. Other stations farther from the lake remained nearly unchanged. The basic model, the linear trend model with lake effect, and the lake-effect-only trend model are compared in the next section.

\section{MODEL VALIDATION}

Interpolation by kriging was applied to: (1) the basic monthly temperature values for all 35 stations from 1900 through May 1993, (2) the monthly temperature values with the linear trend (in latitude and longitude) and lake effect removed and (3) the monthly temperature values with only the lake effect removed. For the data in (2) and (3), the appropriate trend was subtracted from the original data before kriging and was added back afterwards. The 3 models used will be referred to as (1) the ordinary kriging model, (2) the full trend model, and (3) the lake effect trend model.

The cross validation method was used to produce interpolated estimates at all 35 stations over 90 yr for the 3 models. The computer program Geo-EAS (Englund \& Sparks 1988) was used in the cross validation. The source code was modified to make repeated kriging runs and to save the summary statistics for all kriging runs for each model.

Statistics are given comparing the observations with values estimated by the 3 kriging approaches. At the broad level, the relative precision of the 3 models was compared in terms of overall mean error (ME) and mean square error (MSE) (Table 5). The errors are defined so that a positive error is an overestimate and a negative error is an underestimate. The variance of the kriging estimation errors, as computed by GeoEAS, has been included. The ME, of less than $0.03^{\circ} \mathrm{C}$ for all 3 models, indicates that the estimation procedure is unbiased over the domain. The full trend model shows slight decreases in ME and MSE over the ordinary kriging model, and the lake effect trend model shows an even more marked decrease in both $\mathrm{ME}$ and 
Table 5. Comparison of validation error statistics for the 3 models

\begin{tabular}{|lccc|}
\hline Statistics & \multicolumn{3}{c|}{ Model - } \\
\cline { 2 - 4 } & $\begin{array}{c}\text { Ordinary } \\
\text { kriging }\end{array}$ & Full trend & $\begin{array}{c}\text { Lake effect } \\
\text { trend }\end{array}$ \\
\hline Mean error $\left({ }^{\circ} \mathrm{C}\right)$ & 0.029 & 0.027 & 0.016 \\
MSE $\left({ }^{\circ} \mathrm{C}^{2}\right)$ & 0.773 & 0.734 & 0.643 \\
Kriging variance $\left({ }^{\circ} \mathrm{C}^{2}\right)$ & 0.607 & 0.501 & 0.607 \\
\hline
\end{tabular}

Table 6. Range of mean kriging errors $\left({ }^{\circ} \mathrm{C}\right)$ by station and month listed in descending magnitude for mean error $(\mathrm{ME})>\mid 1.00^{\circ} \mathrm{Cl}$. Station numbers are given in parentheses (see Fig. 1)

\begin{tabular}{|c|c|c|}
\hline Weather station & Month & Range of |ME| \\
\hline \multicolumn{3}{|c|}{ Ordinary kriging model } \\
\hline \multicolumn{3}{|c|}{ Overprediction } \\
\hline Grand Marais (14) & May-Aug & $1.60-3.04$ \\
\hline Babbitt (3) & Nov-Feb & $1.19-1.71$ \\
\hline \multicolumn{3}{|l|}{ Underprediction } \\
\hline Two Harbors (31) & Nov-Feb & $1.64-2.22$ \\
\hline Babbitt (3) & May-Jun & $1.19-1.51$ \\
\hline Grand Marais (14) & Dec & 1.38 \\
\hline \multicolumn{3}{|l|}{ Full trend model } \\
\hline \multicolumn{3}{|l|}{ Overprediction } \\
\hline St. Cloud (30) & Dec-Mar & $1.25-1.42$ \\
\hline Itasca (17) & May-Aug & $1.16-1.25$ \\
\hline \multicolumn{3}{|l|}{ Underprediction } \\
\hline Warroad (34) & Nov-Mar & $1.58-2.27$ \\
\hline Two Harbors (31) & May-Jul & $1.43-1.62$ \\
\hline Virginia (32) & May-Jul & $1.16-1.44$ \\
\hline \multicolumn{3}{|c|}{ Lake effect trend model } \\
\hline \multicolumn{3}{|c|}{ Overprediction } \\
\hline Grand Marais (14) & July-Aug & $1.36-1.68$ \\
\hline \multicolumn{3}{|l|}{ Underprediction } \\
\hline None & & \\
\hline
\end{tabular}

MSE. The variance of the estimation errors reflects the uncertainty of the interpolation method - the full trend model shows slightly less variability.

At a more detailed level, the larger mean estimation errors of the 3 models were compared by station and month. Mean kriging errors were checked for large systematic overestimation or underestimation. The station, month, and range of all mean errors above $1.00^{\circ} \mathrm{C}$ in absolute value are given in Table 6 for each model.

In order of importance, the major problem areas for the ordinary kriging model are overpredicting temperature at Grand Marais in the summer and underpredicting temperature at Two Harbors in the winter. Grand Marais has the largest estimation problems (up to $3.04^{\circ} \mathrm{C}$ ), and Two Harbors has the second largest. Errors in the estimation of temperature at these 2 stations, due to Lake Superior, adversely affect the estimation of temperature at Babbitt, inland from the 2 stations.
For the full trend model, a redistribution of the problem areas has occurred. In the winter, temperatures at St. Cloud (the most southerly station) are overpredicted and temperatures at Warroad (the most northerly station) are underpredicted. So, the full trend model, in the influential winter months, has overcompensated for the latitude temperature effect at the extremes. The previous problems with Grand Marais and Babbitt have been corrected, but now there is a moderate overcompensation for the summer cooling effect at Two Harbors and some subsequent problems inland at Virginia. The cooler summer temperatures at Itasca due to the Alexandria Moraine are handled well by ordinary kriging, but adding the linear trend causes problems with the interpolation of this relative minimum.

The lake effect model has reduced the magnitude of both overpredictions and underpredictions. Grand Marais is the only station showing a bias above $1.00^{\circ} \mathrm{C}$ in absolute value. It is still overpredicted in July and August but at half the magnitude as with the ordinary kriging model.

To summarize, both trend models have improved estimation along Lake Superior, but the full trend model has introduced problems with 2 border stations and Itasca. The lake effect trend model has drastically reduced the number of larger mean errors.

\section{TEMPORAL ANALYSIS}

Many climatic variables should presumably be viewed as spatio-temporal phenomena (Rouhani \& Myers 1990). Not only should the spatial domain be considered, but also the time domain. The temporal domain may be comprised of a long-term climatic cycle (Rouhani \& Myers 1990) plus additional year-to-year short-term variation. A practical remedy involves dividing the data set into homogeneous temporal subsets (Rouhani \& Myers 1990). However, the small size of the data set in the spatial domain (35 stations) prohibits estimating monthly variograms. An alternative method is to use a longer time-frame and concentrate on accounting for the long-term trend. It is further assumed that the short-term temporal variation of monthly temperature is much weaker than of monthly precipitation (which can differ greatly due to different orientations and intensities of major storms).

Recent research into the temporal trends in the spatial variability of monthly temperature in the Lake States (Minnesota, Wisconsin, and Michigan) (Holdaway 1995) demonstrated that at closer distances the spatial variability, as measured by the semivariance, has changed over the 19th century. Decadal average monthly semivariances (from 0 to $40 \mathrm{~km}$ ) plotted over 
the century reveal a U-shaped pattern. This century-long trend is fairly consistent across all months, but varies slightly from cool to warm season (Fig. 5). Decadal variograms for the current Minnesota data set confirm the same general trend over all distances-the greatest spatial variability often occurred early and late in the century while the least spatial variability occurred in the 1940 s through the 1960s. Thus, temporal changes in spatial variability show a fairly systematic progression over time, which should enable us to study the changes in the variograms using decadal data.

For each month, the 9 decadal variograms were plotted against distance class, and the 2 decades showing the greatest deviation from the long-term average were identified. The difference in the magnitude of the spatial variability over distance between the 1950 s (low spatial variability) and the recent 1980s (high spatial variability) is given for November (Fig. 6). Decadal variograms for the 2 worstcase scenarios for each month were estimated, and their predictive capabilities were compared with the century-averaged variograms using the final lakeeffect model. The 2 approaches were run using only the 2 extreme decades of each month. The results (Table 7) demonstrate that even when using the most diverse decadal variograms instead of century-averaged variograms, there is no predictive advantage. If fitting decadal variograms to the extreme cases does not increase accuracy and precision, no improvement is expected under more normal conditions.

Why is the model so insensitive to temporal changes in the variogram? In each case the 2 extreme variograms for a month are roughly a multiple of the average variogram. Variograms that only differ in their scale produce the same kriging weights and hence kriging estimations (Isaaks \& Srivastava 1989). Even when variograms deviate slightly from displaying a multiplicative effect, the effect may slightly improve or harm the predictions, but the overall influence remains the same. From the decadal results, we can expect that annual variograms for each month would also be roughly multiplicative and therefore their use would not necessarily improve the predictions.

\section{CONCLUSION}

The empirical variograms for monthly temperature represent the general spatial condition in north central Minnesota over most of the last century. Modeling of

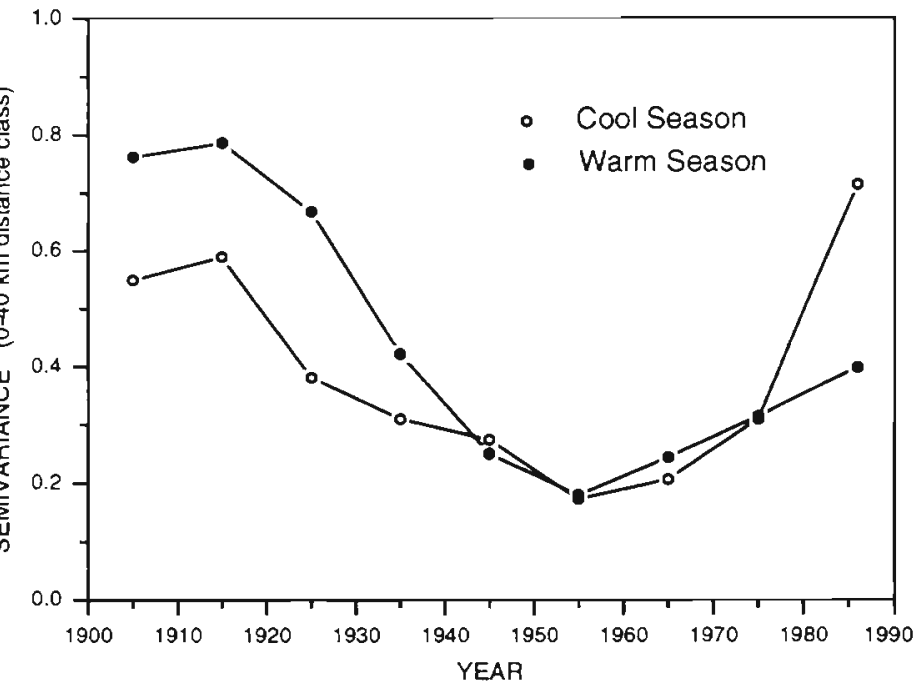

Fig. 5. Spatial variability of monthly temperature over the last century as measured by average semivariance over the Lake States (Minnesota, Wisconsin, and Michigan) by decade. Average semivariances or distance class $0-40 \mathrm{~km}$ plotted separately for cool season months

(September to March) and warm season months (April to August)

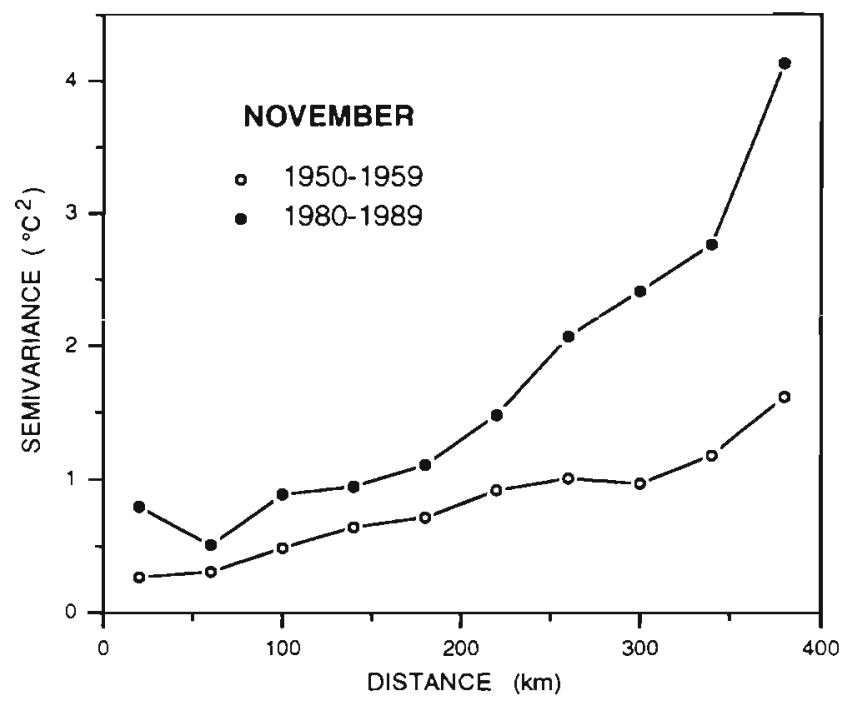

Fig. 6. Average November variograms for Minnesota data for the 2 decades in the century showing the minimum and maximum spatial variability. In November, the extreme decades occurred in 1950-1959 and 1980-1989

Table 7 . Comparison of error statistics for the lake effect trend using century-averaged verses decadal monthly variograms (for extreme cases only)

\begin{tabular}{lcc} 
Statistics & \multicolumn{2}{c}{ Lake effect trend model } \\
& Average variograms & Decadal variograms \\
\hline Mean error $\left({ }^{\circ} \mathrm{C}\right)$ & 0.022 & 0.023 \\
MSE $\left({ }^{\circ} \mathrm{C}^{2}\right)$ & 0.670 & 0.667
\end{tabular}


the anisotropic variograms identified changes in spatial dependence with direction. The variograms reflect the large-scale weather processes resulting from monthly integration of air masses, frontal systems, and common storm tracks. Winter observations (November through March) exhibited an anisotropic variogram with the greatest variability in the NW-SE directionreflecting a trend in monthly temperature values that decreases from SE to NW.

Monthly patterns in the average direction of weather systems and storm systems (as indicated by anisotrophic variograms) also corresponded to the directional influences used in the detrending process. An analysis for large-scale trends in the data revealed that monthly temperatures depend on the latitude (northward displacement) and to a lesser extent longitude (east-west displacement) and that Lake Superior has a notable influence on temperatures of surrounding land areas during certain months of the year. The trend analysis has provided monthly estimates of the magnitude and sign of Lake Superior's influence on temperature for locations adjacent to the lake.

The residual kriging model (with linear trend and lake effect) gave slightly lower mean prediction errors and lower prediction mean square errors than the ordinary kriging model. The improvement was judged too small to warrant the much greater computational effort involved. However, for individuals interested in areas close to Lake Superior, the alternative detrending model using only the lake effect may be of value. It greatly reduced the large mean errors at or near Lake Superior without introducing estimation problems at a few border stations.

These results confirm other findings (Journel \& Rossi 1989) that moderate trends in the data do not significantly affect kriging interpolation if local stationarity exists (Journel \& Huijbregts 1978). But when the trend is a vehicle for summarizing additional information about the natural processes (such as the lake effect), its use may improve the performance of the kriging algorithm (Gambolati \& Volpi 1979).

The variogram has provided a quantitative tool for discussing the inherent structure of the spatial variation in monthly temperature. The spatial patterns found exhibited regional temperature characteristics similar to those found by Baker (Baker \& Kuehnast 1978, Baker et al. 1985). A broad temporal trend in the spatial variability of monthly temperature is evident, but separate estimation of decadal variograms, to account for the temporal effect, is not necessary. Century-averaged variograms were just as accurate. Kriging provides a reliable basis from which to estimate monthly temperature at the forest plot location, thus enabling researchers to study more precisely how climate affects the forest ecosystem.
Acknowledgements. The author gratefully acknowledges the review comments of Michael Richman, Andrew Liebhold, Ricardo Olea, and Richard Rossi. Climatological data were provided by Greg Spoden, Minnesota State Climatologist, whose assistance with the data and state climatology was indispensable. This study was partially funded by the USDA Forest Service Northern Global Change Program.

\section{LITERATURE CITED}

Baker DG, Kuehnast EL (1978) Climate of Minnesota. Part X. Precipitation normals for Minnesota: 1941-1970. Minn Agr Exp Sta Tech Bull 314

Baker DG, Kuehnast EL, Zandlo JA (1985) Climate of Minnesota. Part XV. Normal temperatures (1951-1980) and their application. Agr Exp Sta AD-SB-2777

Baker DG, Strub JH (1965) Climate of Minnesota. Part III. Temperature and its application. Minn Agr Exp Sta Tech Bull 248

Bilonick RA (1983) Risk qualified maps of hydrogen ion concentration for the New York state area for 1966-1978. Atmos Envir 17:2513-2524

Bigg GR (1991) Kriging and intraregional rainfall variability in England. Int J Clim 11:663-675

Bilonick RA (1985) The space-time distribution of sulfate deposition in the northeastern United States. Atmos Envir 19:1829-1845

Burgess TM, Webster R (1980) Optimal interpolation and isarithmic mapping of soil properties. 1. The semivariogram and punctual kriging. J Soil Sci 31:313-331

Chua SH, Bras RL (1982) Optimal estimators of mean areal precipitation in regions of orographic influence. $\mathrm{J}$ Hydrol $57: 23-48$

David M (1977) Geostatistical ore reserve estimation. Elsevier, New York

Delhomme JP (1978) Kriging in the hydro sciences. Adv Water Res 1:251-266

Dingman SL, Seely-Reynolds DM, Reynolds RC III (1988) Application of kriging to estimating mean annual precipitation in a region of orographic influences. Water Resour Bull 24:329-339

Dolph J, Marks D (1992) Characterizing the distribution of observed precipitation and runoff over the continental United States. Clim Change 22:99-119

Englund E, Sparks A (1988) GEO-EAS (Geostatistical Environmental Assessment Software) User's Guide. US Environmental Protection Agency, Las Vegas, NV

Fortin M, Drapeau P, Legendre P (1989) Spatial auto correlation and sampling design in plant ecology. Vegetatio 83:209-222

Gambolati G, Volpi G (1979) A conceptual deterministic analysis of the kriging technique in hydrology. Water Resour Res 15:625-629

Garen DG, Johnson GL, Hanson CL (1994) Mean areal precipitation for daily hydrologic modeling in mountainous regions. Water Resour Bull 30(3):481-491

Holdaway MR, (1995) Spatial analysis of climatic variability in the Lake States since 1900. In: Proceedings of the Ninth Conference on Applied Climatology. January 15-20, 1995. Dallas, TX. American Meteorological Society, Boston, p 357-361

Isaaks EH, Srivastava RM (1989) An introduction to applied geostatistics. Oxford University Press, New York

Journel AG. Huijbregts CJ (1978) Mining geostatistics. Academic Press, New York 
Journel AG, Rossi ME (1989) When do we need a trend model in kriging? Math Geol 21:715-739

Lefohn AS, Knudsen HP, McEvoy LR Jr (1988) The use of kriging to estimate monthly ozone exposure parameters for the southern United States. Environ Pollut 53: $27-42$

Martinez-Cob A, Cuenca RH (1992) Influence of elevation on regional evapotranspiration using multivariate geostatistics for various climatic regimes in Oregon. J Hydrol 136: $353-380$

Phillips DL, Dolph J, Marks D (1992) A comparison of geostatistical procedures for spatial analysis of precipitation in mountainous terrain. Agric For Meteorol 58:119-141

Editor: V. Meentemeyer, Athens, Georgia, USA
Rouhani S, Myers DE (1990) Problems in space-time kriging of geohydrological data. Math Geol 22(5):611-623

Samra JS, Gill HS, Bhatio VK (1989) Spatial stochastic modeling of growth and forest resource evaluation. For Sci 35: 663-676

Seilkop SK, Finkelstein PL (1987) Acid precipitation patterns and trends in eastern North America, 1980-84. J Clim Appl Meteorol 26:980-994

Tabios GQ III, Salas JD (1985) A comparative analysis of techniques for spatial interpolation of precipitation. Water Resour Bull 21:365-380

Webster R, Burgess TM (1983) Spatial variation in soil and the role of kriging. Agric Water Mgt 6:111-122

Manuscript first received: May 22, 1995

Revised version accepted: January 31, 1996 